\title{
Patrimônio iconográfico: um olhar para as pinturas de Pedro Weingärtner como lugar de memória e identidade
}

\author{
Iconographic heritage: a look for Pedro Weingärtner paintings as place of memory and identity
}

\section{Cyanna Missaglia de Fochesatto}

Universidade do Vale do Rio dos Sinos - UNISINOS - São Leopoldo - Rio Grande do Sul - Brasil

Resumo: Pedro Weingärtner foi um artista gaúcho que viveu na transição do século XIX para o século XX. Teve sua trajetória marcada entre as idas e vindas entre Brasil e Europa, bem como a vivência dessas duas culturas. Em sua vasta produção artística retratou, entre outros temas, a imigração europeia. Dessa forma, esta pesquisa visa compreender três pinturas de Weingärtner que contemplem essa temática. As pinturas serão entendidas também como um patrimônio artístico e iconográfico, portador de uma memória, e que retrata uma identidade teuto-brasileira. Isso ocorre, principalmente, ao representar os imigrantes europeus no processo de estabelecimento das primeiras colônias no Sul do Brasil, ou ainda ao representá-los dentro de seus espaços de sociabilidade e lazer, como no caso dos bailes do Kerb.

Palavras-chave: Pedro Weingärtner. Imigração europeia. Identidade. Representação.

\begin{abstract}
Pedro Weingärtner was a gaucho artist who lived in the transition from the nineteenth to the twentieth century. Had its trajectory marked between the comings and goings between Brazil and Europe, and the experience of these two cultures. In his vast artistic production portrayed, among others, the European immigration. Thus, this research aims to understand three paintings Weingärtner that address this issue. The paintings are also understood as an artistic and iconographic heritage and that carries a memory and portraying a German-Brazilian identity. This is primarily to represent the European immigrants in the process of establishment of the first colonies in southern Brazil, or to represent them in their spaces of sociability and leisure, as with the Kerb's dances.
\end{abstract}

Keywords: Pedro Weingärtner. European immigration. Identity. Representation. 


\section{Introdução}

O presente artigo pretende abordar três pinturas do artista gaúcho Pedro Weingärtner que retratem a temática regional. As telas representam o processo de colonização dos imigrantes europeus no Sul do Brasil. Um dos objetivos foi tratar as pinturas também como um patrimônio iconográfico, um lugar de memória e de identidade, em determinado espaço e tempo.

São crescentes as problemáticas levantadas pelos historiadores que têm como fonte de investigação as imagens. Seria possível também citar o museu como fonte de pesquisa para a história em ascensão, já que nas últimas décadas ocorreram aumentos significativos nos trabalhos com essas fontes. Os museus, enquanto instituições interdisciplinares, agregam uma parte relevante do patrimônio cultural e artístico brasileiro. Tratam-se de: "[...] instituições de memória que colecionam, documentam, preservam, exibem e interpretam evidências materiais e informações associadas para o benefício público". (RAMOS, 2010, p. 99). Nesse sentindo, é justificável refletir sobre a transmissão de lembranças e de memórias como fontes de reconstrução do passado pelos artefatos oriundos de museus, acervos e demais espaços de preservação da memória.

A memória apresenta um duplo caminho: o da lembrança e o do esquecimento - que não se faz menos importante. $\mathrm{Na}$ relação memóriaesquecimento os silêncios e as ausências também revelam. Essa relação, igualmente, se manifesta nas pinturas e, da mesma forma, pode ter um significado. Quais os motivos que levaram o artista a retratar "isso" e esquecer de representar "aquilo"? Pois, essas questões geram uma necessidade de aliar ao estudo das iconografias a relação da biografia do pintor com o seu contexto e a sua produção, para termos pistas sobre os motivos de apresentar (ou não) determinados elementos e signos nos seus trabalhos artísticos.

O uso do patrimônio como fonte na historiografia, vindo desde sua origem terminológica, que define patrimônio como bens legados e como uma herança; e passando pelos processos de valorização, escolha, definição, preservação, e pela proliferação dos seus estudos nos últimos anos, Poulot (2009, p.13), define patrimônio da seguinte forma:

[...] pela realidade física de seus objetos, pelo valor estético - e, na maioria das vezes, documental, além de ilustrativo, inclusive de reconhecimento sentimental - que lhe atribui o saber comum, enfim, por um estatuto específico, legal ou administrativo. Ele depende da reflexão erudita e de uma vontade política, ambos os aspectos sancionados pela opinião pública; essa dupla relação é que lhe serve de suporte para uma representação da civilização, no cerne da interação complexa das sensibilidades relativamente ao passado, de suas diversas apropriações e da construção de identidades.

Nesse sentido, é viável entender as pinturas como um patrimônio cultural, e que carecem de atenção e de estudo por parte da disciplina da história, uma vez que as pinturas também guardam uma memória, elas também representam um passado e uma época. As telas tratam de uma memória representada tanto individual - a do próprio pintor quanto uma memória coletiva, ao ser apropriada pelo poder público e utilizada como representação de determinada cultura de uma específica etnia.

As iconografias possuem um olhar pessoal que seria daquele que as pintou. Saber quem fez a obra, o porquê fez, em que circunstâncias, em que contexto foram elaboradas, são fatores fundamentais para as pesquisas que possuem nas pinturas sua fonte principal. As imagens ao longo do século XIX colaboraram para a formação de uma identidade visual do Brasil. Uma possibilidade, nesse sentido, seria refletir sobre as pinturas de Pedro Weingärtner como uma forma de construção de uma identidade para o imigrante europeu. Algumas de suas pinturas possuem um teor político, como por exemplo, Tempora Mutantur (1898). Essa pintura ao ser adquirida pelo governo do Estado - no intuito de ficar exposta representando determinado grupo de imigrantes, no Rio Grande do Sul, busca reforçar a imagem do imigrante trabalhador que vence, apesar 
das dificuldades, a natureza selvagem. Outro exemplo refere-se a tela Vida Nova (1893), que representa a identidade do imigrante europeu ao chegar no Novo Mundo para construir as primeiras moradias, as primeiras vilas, possuindo assim a identidade do imigrante que traz consigo o progresso. Assim, as imagens também adquirem um sentido de patrimônio iconográfico e cultural.

[...] Podemos ver nas imagens não apenas o que elas procuraram mostrar no passado, sua circulação e seus usos sociais, mas também aquilo que posteriormente se buscou nessas imagens, como monumentos visuais. Nessa perspectiva, a identificação e o estudo da iconografia relacionada ao processo de construção de uma visualidade para os bens simbólicos da nação adquirem densidade própria. A noção de patrimônio, por si só problemática, ao invés de ser tomada como um elemento estático e imutável da análise histórica apresenta-se então como um processo social, construído no tempo e no espaço, por práticas e representações diversas, em que se destacam. (TURAZZI, 2009, p.54).

É factível pensar de que forma as pinturas de artista Pedro Weingärtner podem ser utilizadas como fonte de estudo da história. O artista retratou uma sociedade em construção, retratou a chegada de imigrantes europeus no Rio Grande do Sul e em Santa Catarina, a forma que os imigrantes se estabeleceram no Sul do país, as suas práticas cotidianas e culturais, as festas e bailes, o interior de vendas e demais símbolos socioculturais do imigrante. Todas essas representações elucidam a vida cotidiana e a cultura dos europeus que chegaram ao Brasil, além de mostrar aspectos da formação da sociedade gaúcha, na transição do XIX para o século XX. No entanto, essas pinturas não podem ser vistas como verdades absolutas ou retratos inquestionáveis, mas, sim, podem ser investigadas como uma forma de representação de uma determinada época, como uma memória intencionalmente produzida, e que resulta em um patrimônio iconográfico.

Pedro Weingärtner foi um pintor de origem alemã, nascido no Rio Grande do Sul, em 1853. Iniciou seus estudos no Brasil, mas aprimorou sua técnica na Europa, sendo neste último local onde viveu boa parte de sua vida e estabeleceu o seu atelier. Gostava de retratar o que seu olhar captava, tinha gosto por pinturas narrativas e bem detalhadas, sempre partindo de esboços prévios ou mesmo de fotografias. Pintou temáticas regionais, como o imigrante, o gaúcho, a vida cotidiana e social riograndense e as paisagens. Retratou também os temas clássicos e mitológicos. Weingärtner viveu entre a transição do século XIX para o XX, morrendo em Porto Alegre, no ano de 1929. (GUIDO, 1956).

Nas linhas que seguem três pinturas de Pedro Weingärtner serão analisadas no intuito de discutir o processo de representação e identidade do imigrante europeu, na região Sul do país.

\section{Tela Tempora Mutantur (1898)}

$\mathrm{Na}$ primeira imagem, Tempora Mutantur ${ }^{1}$, pintada em Roma, no ano de $1898^{2}$, estaria sendo apresentada a dificuldade vivida pelos imigrantes recém-chegados ao Estado do Rio Grande do Sul. O cenário foi retratado como um ambiente agreste, em uma zona serrana de colonização, onde uma vasta mata que contorna a pintura aparece como um indicativo do trabalho que os imigrantes teriam tido pela frente. A tela traz o início do processo de colonização alemã no Sul do país, e remete a ideia de dificuldade e até de desilusão, em um momento de pausa do trabalho ao cair da tarde, que fica marcado pelo rosado do céu ao fundo da tela. O visível trabalho braçal, típico do labor rural, e necessário aos imigrantes que têm por pretensão se estabelecer na colônia, caracterizou essa obra. Os sulcos abertos na terra para o provável plantio, e os troncos caídos ao chão no segundo plano da pintura, demonstram parte do esforço físico feito pelos personagens ao longo do dia, o que acentua o discurso do imigrante trabalhador.

\footnotetext{
${ }^{1}$ Esse quadro teria tido sua inspiração na pintura O Ângelus, de Millet.

${ }^{2}$ Em 1899, Weingärtner expôs o quadro na litografia da família, tendo de imediato uma boa repercussão da mídia. No mesmo ano a tela foi adquirida por Borges de Medeiros para ficar exposta no Palácio do Governo. (GUIDO, 1956).
} 
Figura 1: Tempora Mutantur, 1898.

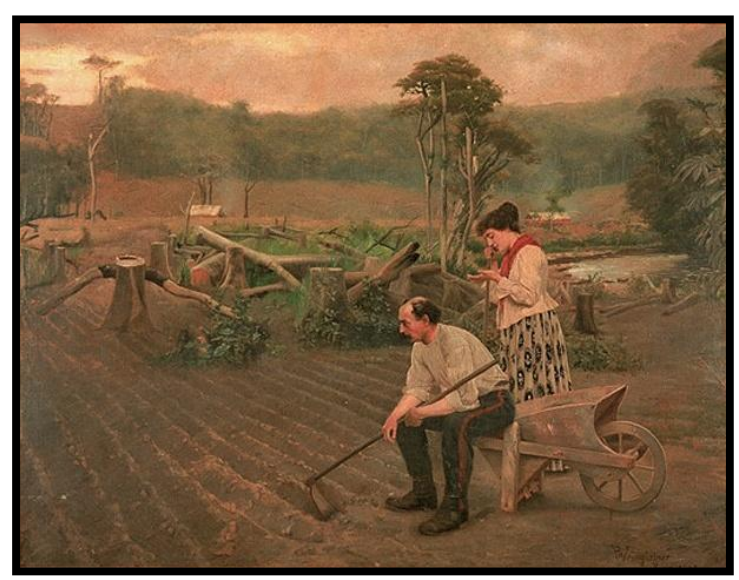

Fonte: Museu de Arte do Rio Grande do Sul Ado Malagoli. Porto Alegre, RS.

Pedro Weingärtner tinha gosto pela pintura narrativa e pelo detalhe em suas obras. Isso aparece em quase todas as suas produções. A tela Tempora Mutantur seria uma narrativa: Weingärtner teria retratado um casal que perdeu tudo na Europa, sendo essa a inspiração do pintor. Os personagens teriam vindo para a colônia após o homem perder seu dinheiro no jogo, tratando-se também de um desafeto do artista, conforme foi narrado em uma carta do próprio pintor a um amigo. (GUIDO, 1956, p. 92-93).

Outro aspecto de destaque seria a postura do personagem masculino e a sua expressão de cansaço. Teriam - os dois personagens da tela trabalhado exaustivamente o dia todo, pois, observase que a mulher analisa em suas mãos os calos dos primeiros dias de trabalho de sua vida com uma certa expressão de desgosto. Assim, cansaço e o desamino, assinalam a expressão do casal na pintura. No entanto, é possível notar que a representação da tela remete ao processo de trabalho rural, mas também ao desbravamento da mata brasileira, e a possibilidade de trazer o progresso e a civilização para um terreno tortuoso como o apresentado na pintura.

O próprio cenário de Tempora Mutantur é outro fator de destaque. Foi retratado o modo de vida desses primeiros imigrantes, apresentando as casas simples ao fundo da tela com fumaça saindo das chaminés. O cenário seria um elemento importante para a interpretação dos costumes e representações do Rio Grande do Sul. Essa pintura possui por norte um tom melancólico, onde os colonos aparecem desprovidos de otimismo e heroicidade. O quadro também estaria ligado ao discurso do imigrante trabalhador, já que esse aspecto foi bastante pontual nessa representação. A escolha por retratar uma cena de trabalhadores do campo seria um reflexo de como estavam fazendo, na mesma época, muitos pintores realistas europeus. (BOHNS, 2008).

São vastas e plurais as interpretações que uma obra de arte permite ao pesquisador inferir. Essa pintura foi marcada pelo tom pessimista que apresentou as desventuras do trabalho no campo dos imigrantes europeus que chegavam ao Rio Grande do Sul, na segunda metade do século XIX. Evidenciou também o trabalho como uma parte formadora da identidade desses imigrantes, tal qual uma narrativa visual de um discurso que pretende colocar esse tipo social como o provedor do progresso e da civilização, pois eles estariam vencendo, apesar do cansaço, a vasta e exuberante natureza brasileira.

É possível, nesse caso, compreender as imagens como uma memória produzida intencionalmente. Onde um indivíduo que representa a sua memória - seja ela ora individual ou ora coletiva - ou ainda uma memória individual que se tornou coletiva no momento que determinados grupos (nesse caso os teuto-brasileiros) passam a se identificar com a memória individual de Weingärtner, e a (re)apropriam. Ou ainda, quando o Governo do Estado adquiriu essa pintura para a exposição nos espaços públicos do Rio Grande do Sul, nesse sentido, buscou também torná-la um patrimônio artístico, além de uma memória do grupo teuto, que foi narrada por meio das telas e dos pincéis.

As articulações entre memória individual e coletiva são abordadas a partir do momento em que, embora o indivíduo traga consigo a lembrança, a mesma está sempre interagindo com a sociedade, pois: "[...] nossas lembranças permanecem coletivas e nos são lembradas por outros, ainda que se trate de eventos em que somente nós estivemos envolvidos e objetos que somente nós vimos". (HALBWACHS, 2006, p. 30). Já a memória individual estaria 
vinculada a diferentes contextos e participantes, podendo ocorrer uma transposição da memória pessoal ao convertimento de um conjunto de acontecimentos compartilhados por um ou mais grupos, sendo assim, ela transmutaria de individual para coletiva. (HALBWACHS, 2006, p. 29-30). Dessa forma, a memória coletiva representa a memória de um grupo, onde cada indivíduo deve se identificar com ela. Tratando-se da memória que o pintor pretendeu exprimir na arte, pode-se afirmar que:

\begin{abstract}
O processo de recordar é uma das principais formas de nos identificarmos quando narramos uma história. Ao narrar uma história, identificamos o que pensamos que éramos no passado, quem pensamos que somos no presente e o que gostaríamos de ser. As histórias que relembramos não são representações exatas do nosso passado e nos moldam para que se ajustem às nossas identidades e aspirações atuais. Assim, podemos dizer que nossa identidade molda nossas reminiscências; quem acreditamos que somos no momento e o que queremos ser afetam 0 que julgamos ter sido (THOMSON, 1997, p. 57).
\end{abstract}

A memória foi colocada não apenas como uma possibilidade de lembrar o passado, mas principalmente de construir uma memória desejada, e uma representação do passado. Refletindo acerca da memória, Ramos considera:

\begin{abstract}
Coletiva, individual, ou social, a memória pode ser vista como um sistema em que se cruzam estruturas culturais, políticas e econômicas como códigos de representação. Isso quer dizer que as representações do passado e do presente, bem como as idealizações do futuro, também convivem na memória, conferindo ao indivíduo identidade cultural e grupal. Logo, é por estar inscrita na cultura e ser produtora de processos culturais que a memória é sempre um reviver, ou seja, um repensar, que com imagens, quer com conceitos, com práticas, objetos ou ideias. (RAMOS, 2010, p. 103).
\end{abstract}

Nas palavras de Candau (2011, p. 10) temos uma reflexão sobre a transmissão da memória: "Transmitir uma memória e fazer viver, assim, uma identidade, não consiste, portanto, em apenas legar algo, e sim uma maneira de se estar no mundo". Nesse sentido, podemos pensar as telas de
Weingärtner também como parte da sua vivência enquanto descendente de imigrantes alemães.

$\mathrm{Na}$ pintura a seguir o processo de colonização será novamente representado, ainda que tenha sido retratado de forma bastante distinta da tela Tempora Mutantur, evidenciando o início do processo de colonização em Nova Veneza, Santa Catarina.

\section{Tela Vida Nova (1893)}

A pintura intitulada Vida Nova, de 1893, representa a instalação dos primeiros imigrantes europeus ao chegarem no Estado de Santa Catarina. Esse quadro foi bastante representativo da vida cotidiana, dos aspectos culturais, e do modo de vida dos colonos recém-chegados. É possível observar como era a vida desses imigrantes no início da colonização, as suas vestimentas simples, a plantação e a colheita, o desmatamento necessário para o seu assentamento e o fogo de chão. Todos esses elementos foram retratados pelo pintor Pedro Weingärtner com uma grande riqueza de detalhes. A pintura mostra o início da organização espacial da colônia de Nova Veneza, trazendo todos afazeres cotidianos que estruturavam a vida no local. Tarasantchi discorre sobre a visita do pintor em Santa Catarina, ao final do século XIX: “[...] Weingärtner costumava embrenhar-se pelo interior, tendo chegado até Santa Catarina. Foi lá que um dia vislumbrou o surgimento de Nova Veneza e o flagrou numa pintura magnífica que chamou de Vida Nova". (TARASANTCHI, 2009, p.116). 
Figura 2: Vida Nova, 1893 (Nova Veneza).

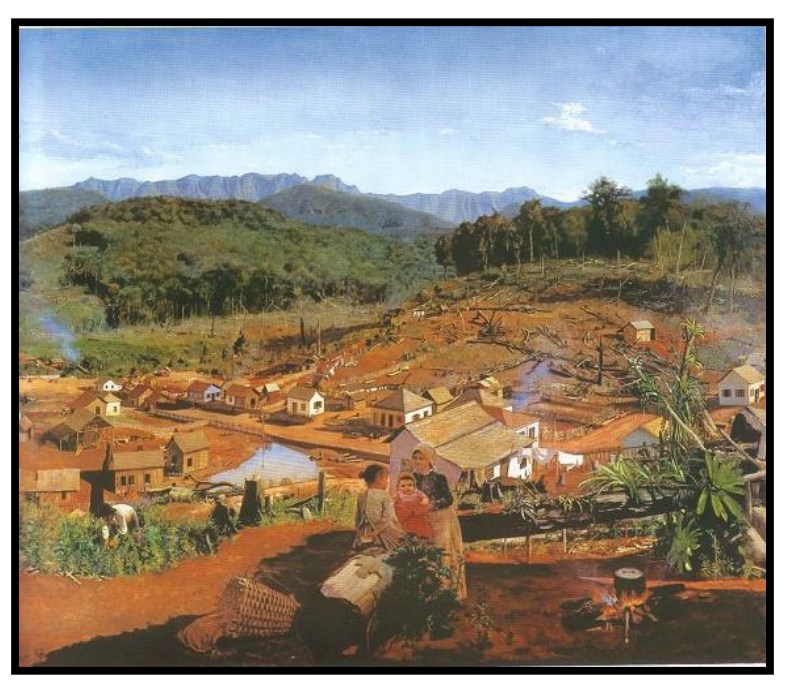

Fonte: Acervo da prefeitura de Nova Veneza, Santa Catarina.

A pintura possui três planos distintos. No primeiro plano nota-se uma mulher e duas menininhas sorridentes, cestos de roupa para lavar, e um fogo de chão no canto direito da tela. As casinhas vão dando contorno ao cenário em formação, mostrando a estrutura física da comunidade europeia que se estabeleceu nessa região. A natureza também se estaca no primeiro plano, onde é possível perceber algumas árvores fazendo sombra e muitos troncos cortados, que representam 0 desmatamento necessário para o estabelecimento dessas novas famílias. Uma pequena horta, homens trabalhando com carroças cheias de madeira e feno, além das roupas estendidas nos varais, são elementos que vão formulando como era a vida cotidiana dos imigrantes, e a forma que esse grupo vivia.

No segundo plano da pintura pôde-se notar o surgimento de Nova Veneza de forma mais intensa. As casas simples de madeira, desorganizadas sob um chão de terra vermelha irregular, pontuam a construção da colônia. Além disso, vê-se diversos troncos de árvores cortadas e espalhadas sobre 0 chão de terra batida. Quase todas as casas mostram "os afazeres de seus moradores e as atividades que desenvolvem no seu entorno". (TARASANTCHI, 2009, p. 118). A representação do trabalho no campo demonstra a forma de subsistência desses grupos de imigrantes. Foi por meio das atividades rurais que as colônias foram se formando. Sobre o retrato do imigrante associado ao trabalho agrícola, bem como as construções das suas moradias, conforme discorre Tramontini, parece ter sido esse o cenário que também foi retratado por Weingärtner em Vida Nova:

A roça nova na mata virgem é conquistada a ferro e fogo: o machado, para obter os gigantes da selva; as queimadas, para oferecer o espaço necessário ao plantio. Por entre os troncos carbonizados planta-se o primeiro feijão, o milho e demais produtos da terra. A falta de experiência acarreta muitas decepções quanto a esperada colheita. À medida que o pioneiro da nossa agricultura se vai sintonizando com 0 ambiente, suas colheitas e toda a situação vão melhorando visivelmente. (TRAMONTINI, 1994, p. 54).

O terceiro plano da pintura traz a natureza brasileira. Seria um indicativo do desafio que esperava esses imigrantes, no sentido de ter que eliminar a mata para a sua própria sobrevivência. Novamente os detalhes chamam a atenção do expectador, pois são minuciosamente executados, e, além disso, trazem uma riqueza de informações sobre o modo de vida dos primeiros habitantes. Como eram as primeiras casas, as vestes, o terreno e as atividades diárias são aspectos retratados na pintura, e que fornecem um material visual significativo sobre a imigração europeia em Santa Catarina.

A última tela analisada nesta pesquisa aprofunda aspectos socioculturais da vida dos imigrantes europeus no Rio Grande do Sul, uma vez que representa o baile do Kerb, um espaço de sociabilidade dos teuto-brasileiros.

\section{Tela Kerb (1892)}

A pintura intitulada de $K e r b^{3}$, do ano de 1892 , designa uma espécie de festa religiosa - ao menos em sua origem - e também familiar. O Kerb foi uma das maiores festas da colônia alemã, tendo uma duração de até três dias, ainda que seus preparativos pudessem levar meses. A organização da festividade

\footnotetext{
${ }^{3}$ Foi incorporada como uma atividade característica das comunidades de imigrantes alemães, que introduziram a mesma em território brasileiro.
} 
era cuidadosamente elaborada, desde a decoração até a alimentação, que era sempre abundante e farta. Roupas novas também eram feitas ou compradas para a utilização no baile, já que marcavam o status social da pessoa ou da família. O período de trabalho era interrompido e somente retomado após o final da festividade, os parentes e amigos vinham de longe para participar da missa e da comemoração. Ficavam hospedados com os parentes mais próximos, e também ajudavam nos preparativos. (WOLFF; FLORES, 1994, p. 208).

Essa pintura possui aspectos diferentes das outras duas obras apresentadas anteriormente, pois está sendo representado um ambiente interno, onde um número maior de personagens foi apresentado. Além disso, foi possível notar a interação entre os indivíduos da tela - demarcando a importância do baile como espaço social da colônia. Essas festas desempenhavam um importante papel na sociabilidade dos imigrantes, pois além de simbolizar um ambiente para conversar e dançar, o arranjo de casamentos ou contratos de negócios também eram discutidos e fechados através destes bailes.

Figura 3: Kerb, 1892.

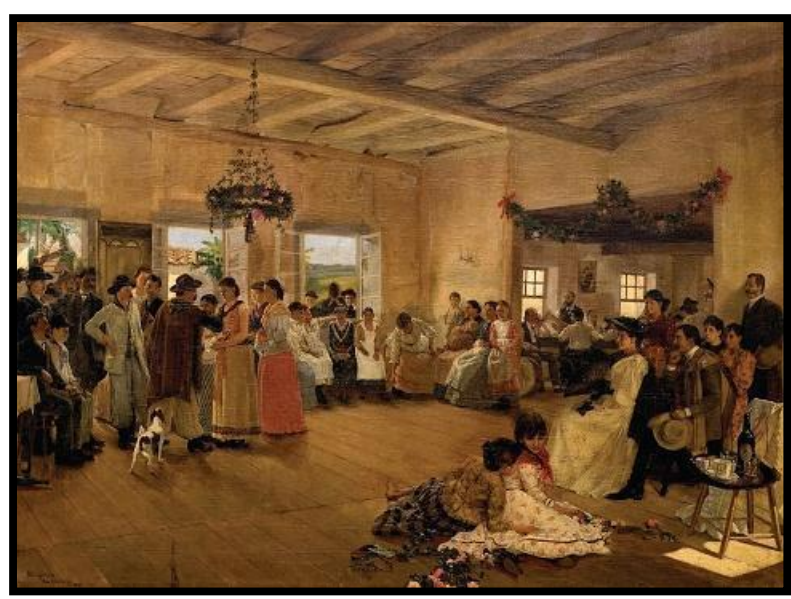

Fonte: Coleção Sergio e Hecilda Fadel. Rio de Janeiro, RJ.

Essa pintura apresenta relevantes informações das cenas da cultura e do cotidiano do Rio Grande do Sul, do final do século XIX, ao mostrar a festa tradicional dos colonos, em Novo Hamburgo. Guido descreve a cena da seguinte forma:
É o momento em que vão começar as danças: várias senhoras, garotos e cavalheiros estão sentados em redor da ampla sala; duas meninas, no chão, brincam, em primeiro plano. À direita observa-se um grupo no qual um homem de botas, sentado, segura 0 queixo com uma das mãos e observa, ao que parece vivamente interessado. Junto dele, toda de claro na sua vaporosa toilette antiga, de leque escuro na mão enluvada e de chapéu, formosa jovem de tipo germânico olhava sorrindo para um grupo de moças e de homens à esquerda. (GUIDO, 1956, p. 61).

Estão presentes na tela Kerb dois tipos sociais que contribuíram para a formação étnico-cultural do Estado: o gaúcho e o imigrante alemão, que interagem no mesmo ambiente. Do lado direito da tela nota-se um grupo de imigrantes possivelmente estabilizados financeiramente, o que fica evidente devido a vestimenta fina, aos sapatos e chapéus, demarcando a importância das vestes e acessórios como símbolos do status social de uma família. No lado esquerdo da pintura identifica-se um grupo de gaúchos conversando animadamente com algumas moças, provavelmente convidando-as para uma dança.

Essa representação contribuiu para a formulação de uma identidade distinta daquelas vistas nas imagens anteriores. Os imigrantes aparecem agora em um momento de confraternização e de lazer, longe do trabalho rural. Mostra uma cultura do imigrante trazida da Europa se propagando na nova colônia, e não apenas isso, mas mostra a interação cultural dos grupos sociais distintos. Traz ainda embora do lado de fora da festa - o personagem negro, que não participa desse espaço, pois o baile seria o local de manutenção identitária alemã.

Discorrendo sobre a importância dos clubes especificamente o Orpheu - entre as sociedades teuto-brasileiras enquanto espaços de sociabilidade e de lazer, pode-se afirmar:

As novas sociedades usavam, de início, como seu espaço de lazer, a sede da Sociedade Orpheu, tornando-a a mais concorrida das sociedades do centro urbano leopoldense. Banquetes, bailes, festivais, teatro, concertos, kerb, tudo acontecia em seus salões. Era o "espaço-mor" da sociabilidade, nesse período, e, portanto, o espaço de visibilidade das elites leopoldenses. Isso possibilitava ao Clube 
abrigar os diferentes segmentos sóciopolíticos urbanos de São Leopoldo porque eram todos oriundos de uma mesma matriz: a elite teutobrasileira. (RAMOS, 2000, p. 233).

Nesse sentindo, a produção de uma identidade pode também ser conflitante, já que nem sempre a identidade ajuda a incluir ou torná-la parte do grupo, mas também ela tem o poder de excluir. No caso dessa tela, a personagem negra que espia a festa da janela, parece não fazer parte da identidade formada dentro do ambiente que ocorre o baile Kerb, onde os colonos aproveitam o espaço para reafirmar a sua identidade e a sua cultura. A festa é uma forma de expressão e de manutenção dos vínculos sociais e afetivos, de encontro dos pares. Durval Muniz de Albuquerque Júnior ao fazer uma revisão da literatura sobre o significado das festas as discute como uma mescla entre a brasilidade e o europeu, e como um jogo de força entre os dominados e os dominantes: "[...] o evento festivo [...] permite acessar práticas e significações do mundo dos dominados, práticas e significações em conflito e muitas vezes rebeldes, mas sempre de resistência às práticas e significações das elites sociais". (JÚNIOR, 2011, p. 141). Já Vania Inês Avila Priamo afirma sobre as festas Kerb e Kolonie, em Nova Hartz, que: "Estes espaços de sociabilidade possuem normas de conduta, sejam eles espaços formais [como clubes, sociedades, maçonaria, igrejas] ou informais [como bares, ruas, parques e praças]. Estas normas podem ou não ser obedecidas". (PRIAMO, 2013, p. 154). A festa também serve como ponto de ajuda mútua, como um local de formação de redes sociais, fundamentais no período da segunda metade do século XIX e início do século $X X$.

\section{Considerações finais}

As três pinturas investigadas nesta pesquisa destacam o imigrante europeu em situações distintas. Tempora Mutantur e Vida Nova representam cenários externos, onde mostram a vida rural. Ambas as telas apresentam 0 imigrante em processo de estabelecimento, e vão dando destaque ao trabalho no campo e ao processo de agricultura. Buscam retratar uma identidade onde o imigrante vem trazendo a civilização e o progresso através do trabalho rural e da construção das primeiras colônias. Já a pintura Kerb segue em outro sentido, ela mostra um momento de lazer e de prazer em um espaço de sociabilidade, onde é viável perceber aspectos sociais e culturais bem acentuados nessa pintura, principalmente referente às vestes e a interação da comunidade com o espaço social.

Foi possível questionar onde a própria memória do pintor estava representada nas telas. Sabendo que Weingärtner era filho de imigrantes alemães, também se pôde inferir sobre a memória e a própria percepção de imigração que o pintor possuía. Sendo ele um filho de imigrantes - que ao chegarem ao Brasil passaram, igualmente, por dificuldades torna-se um indício dos motivos que levaram Weingärtner a retratar os imigrantes de determinada maneira. Assim, seus trabalhos também podem ser considerados respingos de sua memória e de sua própria trajetória enquanto artista plástico e descendente de alemães.

Percebeu-se, ao longo da análise da imagem do imigrante europeu, que Weingärtner representou a dificuldade que esses primeiros colonos passaram na tentativa de estabelecimento e de colonização da região Sul do país. O trabalho duro na terra foi simbolicamente exposto na pintura Tempora Mutantur, perceptível nas expressões do casal: o homem cansado e a mulher refletindo sobre as mãos calejadas. A pintura Vida Nova apresentou o imigrante se estabelecendo no território de Santa Catarina para o início da colonização. desmatamento, as primeiras moradias simples, o estilo de organização social, o cenário e a ocupação estão presentes nessa obra. Já a tela Kerb, que trata de um momento mais positivo desse grupo étnico se comparado a pintura Tempora Mutantur, pois, retrata o lazer e o espaço de sociabilidade do grupo teutobrasileiro. Apresenta uma tradicional festa que foi inserida pelos próprios imigrantes na região Sul, e que perdura até a atualidade. No entanto, o colono mostrado como 0 pequeno proprietário se estabelecendo, o trabalhador inesgotável voltado a 
atividade agrícola, cumpre o papel de formação de uma identidade e de uma representação de um grupo social que teria colaborado para o desenvolvimento do Estado do Rio Grande do Sul e de Santa Catarina.

\section{Referências}

BOHNS, Neiva Maria Fonseca. Realidades simultâneas: Contextualização histórica da obra de Pedro Weingärtner. 19\&20, Rio de Janeiro, v. III, n. 2, abr. 2008. Disponível em: <http://www.dezenovevinte.net/artistas/artistas nb w eingartner.htm>. Acesso em 12 de junho de 2015 .

CANDAU, Jöel. Memória e identidade. São Paulo: Contexto, 2011.

CERTEAU, Michel de. A cultura no plural. Campinas. SP: Papirus, 1995

GUIDO, Ângelo. Pedro Weingärtner. Porto Alegre: Divisão de Cultura - Diretoria de Artes da Secretaria de Educação e Cultura, 1956.

HALBWACHS, Maurice. A memória coletiva. Trad. de Beatriz Sidou. São Paulo: Centauro, 2008.

JUNIOR, Durval Muniz de Albuquerque. Festas para que te quero: por uma historiografia do festejar. In: Patrimônio e memória. UNESP - FCLAs - CEDAP, v.7, n.1, jun. 2011, p. 134-150.

POULOT, Dominique. Uma história do patrimônio no Ocidente, séculos XVIII-XXI: do monumento aos valores. São Paulo: Estação Liberdade, 2009.

PRIAMO, Vania Inês Avila. Entre a história e o turismo: as cidades e seu patrimônio cultural (Nova Hartz-RS). 2013. 235 f. Dissertação (Mestrado em História). Programa de Pós-Graduação em História, Universidade do Vale do Rio dos Sinos - UNISINOS, São Leopoldo, RS, 2013.

RAMOS, Eloisa Helena Capovilla da Luz. O teatro da sociabilidade: os clubes sociais como espaço de representação das elites urbanas alemãs e teutobrasileiras - São Leopoldo 1858-1930. 2000. 275 f. Tese (Doutorado em História). Programa de PósGraduação em História. Universidade Federal do Rio Grande do Sul - UFRGS, Porto Alegre, RS, 2000.

RAMOS, Eloísa Helena Capovilla da Luz. Os museus de imigração como espaços da memória. In: MARTINS, Ismênia de Lima e HECKER, Alexandre (Orgs.). E/imigrações: histórias, culturas, trajetórias. 1.ed. São Paulo: Expressão e Arte, 2011. p. 99-112.

TARASANTCHI, Ruth Sprung. Pedro Weingärtner 1853-1929: Um artista entre o Velho e o Novo Mundo. São Paulo: Pinacoteca do Estado, 2009.
THOMSON, Alistair. Recompondo a Memória. Questões sobre a relação entre a História Oral e as Memórias. In: Revista Projeto História. v. 15, p. 51 84. São Paulo: abr. 1997.

TRAMONTINI, Marcos Justo. A questão da terra na fase pioneira da colonização. In: VASCONCELLOS, Naira; MAUCH, Claudia. (Org.). Os alemães no Sul do Brasil: cultura, etnicidade e história. Canoas: ed. ULBRA, 1994.

TURAZZI, Maria Inez. Iconografia e Patrimônio: O Catálogo da Exposição de História do Brasil e a fisionomia da nação. RJ: Fundação da Biblioteca Nacional, 2009.

WOLFF, Cristina Scheibe; FLORES, Maria B. Ramos. A Oktoberfest de Blumenau: turismo e identidade étnica na invenção de uma tradição. In: VASCONCELLOS, Naira; MAUCH, Claudia. (Org.). Os alemães no sul do Brasil: cultura, etnicidade e história. Canoas: ed. ULBRA, 1994. 